\title{
Subclinical Central Lymph Node Metastasis in Papillary Thyroid Microcarcinoma Evaluated as cT1aNO by Preoperative Imaging Study
}

\author{
Seung Tae Kim¹, Bong Kwon Cheon ${ }^{2}$, Hyoung Shin Lee ${ }^{1}$, Sung Won Kim ${ }^{1}$, \\ Hyo Sang Park ${ }^{1}$ and Kang Dae Lee ${ }^{1}$ \\ Department of Otolaryngology-Head and Neck Surgery1, Department of Pathology², Kosin University Gospel Hospital, \\ Busan, Korea
}

\begin{abstract}
Background and Objectives: Papillary thyroid microcarcinoma (PTMC) generally has a highly favorable prognosis, however reports show a $30-65 \%$ prevalence of subclinical central lymph node metastasis. Therefore, the role of elective central neck dissection in PTMC treatment remains controversial. Our study focused on preoperative features of clinically lymph node negative and intracapsular (cTlaNO) PTMC and the correlation of these features with subclinical central lymph node metastasis. Materials and Methods: Of 584 PTC patients who underwent thyroidectomy at the Kosin University Gospel Hospital from January 2009 to July 2011, 219 patients with CTlaNO PTMC were reviewed retrospectively. Pathologic results were reviewed and various clinicopathologic prognostic factors were investigated. Results: Postoperative pathology report revealed capsular invasion of primary tumor in 77 patients (35.2\%) and subclinical central lymph node metastasis in 62 patients (28.3\%). Tumor of the isthmic location was an independent predictor of subclinical central lymph node metastasis by multivariate analysis while multifocality showed borderline significance. The presence of extrathyroidal extension (ETE), multifocality, and cervical lymph node metastasis were significantly related to PTMC of isthmus. Seven of the 14 subjects with PTMC of the isthmus (50\%) had pretracheal lymph node metastasis showing significant correlation $(p=0.001)$. Conclusion: Despite the absence of ETE and lymph node metastasis in the preoperative imaging studies, higher risk of subclinical central lymph node metastasis should be considered in PTMC with multifocality and tumor of the isthmus.
\end{abstract}

Key Words: Papillary thyroid microcarcinoma, Neck dissection

\section{Introduction}

Papillary thyroid microcarcinoma (PTMC) is defined as a papillary thyroid carcinoma (PTC) $10 \mathrm{~mm}$ or smaller in the greatest diameter.' Increased use of high resolution ultrasonography (US) have led to increase PTMC detection. ${ }^{2)}$ Although PTMC generally has a highly favorable prognosis, however reports show a 30-65\% prevalence of subclinical central lymph node metastasis. Therefore, the role of surgical intervention in PTMC treatment remains controversial, especially in the elective central neck dissection (CND). ${ }^{3,4)}$ Based on the American Thyroid Association (2009) guideline, thyroidectomy without CND may be appropriate for patients with small (T1 or T2) low-risk, noninvasive, clinically NO PTC. ${ }^{1)}$ The routine CND in clinically node-negative PTMC has little oncologic

Received April 22, 2013 / Revised September 22, 2013 / Accepted September 24, 2013

Correspondence: Kang Dae Lee, MD, PhD, Department of Otolaryngology-Head and Neck Surgery, Kosin University Gospel Hospital, Amnam-dong 34, Seo-gu, Busan 602-702, Korea

Tel: 82-5l-990-6470, Fax: 82-5l-245-8539, E-mail: kdlee@gmail.com

Copyright @ 2013, the Korean Thyroid Association. All rights reserved.

(a) This is an open-access article distributed under the terms of the Creative Commons Attribution Non-Commercial License (http:// creativecommons.org/licenses/by-nc/3.0/), which permits unrestricted non-commercial use, distribution, and reproduction in any medium, provided the original work is properly cited. 
outcome evaluations with prospective designed studies and some possibility of CND complications. But some authors advocate prophylactic CND due to frequent lymph node metastasis in patient with PTMC and also other studies report the long term recurrence rate of PTMC as up to $10 \%$.

Several studies on clinicopathologic factors related to subclinical central lymph node metastasis in PTMC have been reported. However, among those studies results have been inconsistent and mainly focused on postoperative pathologic factors. ${ }^{1-8)}$

We focused on preoperative features of cT1aNo PTMC, mainly from high resolution US, and the correlation of these features with subclinical central lymph node metastasis. Also the correlation of the pattern of central cervical metastasis and the extent of CND was evaluated.

\section{Materials and Methods}

A total of 584 patients diagnosed with PTC underwent thyroidectomy from January 2009 to July 2011. Of these 584 patients, 314 were diagnosed PTMC by a single radiologist using US before the surgery. Of these, 95 patients who had clinically extrathyroidal extension (ETE) and/or $N$ positive disease from routine staging US and neck CT, were excluded. In this study, 219 patients with cT1aNO PTMC were reviewed retrospectively.

Total thyroidectomy was performed in the presence of contralateral large goiter, multifocality, isthmus involvement, intra-operative detection of ETE, or lymph node metastasis.

All patients underwent CND, but the contralateral paratracheal lymph node was dissected when there was a bilateral lesion, a tumor involving the isthmus, or suspicious lymph nodes metastasis. Various clinicopathologic prognostic factors, such as age, gender, T stage, N stage, tumor location, multifocality, and CND extent were investigated. The location of solitary thyroid cancers was classified as upper third, middle third, lower third, or isthmus. The number of lymph node metastasis and lymph node density (LD; number of $L N$ metastasis/ $L N$ yield) were measured after re- viewing pathologic results.

Statistical analysis was performed using SPSS 18 (SPSS Inc., Chicago, IL, USA) with chi-square test (univariate) and binary logistic regression (multivariate), and statistical significance was determined when p-value was less than 0.05 .

\section{Results}

Of the 219 patients diagnosed with cT1aNO PTMC, $34(15.5 \%)$ were male and 185 (84.5\%) were female (ratio, $1: 5.4)$. The mean age at initial treatment was 47.7 years (range, 18 to 75 years). The largest dimension of primary tumors ranged from 1 to $14 \mathrm{~mm}$, with a mean of $6.4 \mathrm{~mm}$ postoperatively, and there was no significant difference in preoperative and postoperative tumor sizes. 45 subjects $(20.5 \%)$ had multifocal lesions preoperatively, with a mean of 2.04 lesions (range, 2 to 3 ) per subject. Postoperative pathology report revealed capsular invasion of primary tumor in 77 patients (35.2\%) and subclinical central lymph node metastasis in 62 patients (28.3\%). The mean number of dissected lymph nodes in the central compartment was 6.69 (range, 1 to 34). The mean number of positive central node metastasis was 2.08 (37 subjects had single LN metastasis, 25 had $\geq 2$ LN metastasis). The mean LD was 0.39 (range, 0.03 to 1$)$; 38 subjects (61.3\%) had a LD of 0.5 or less and 24 (38.7\%) had an LD between 0.5 and 1 .

Univariate analysis showed that the frequency of lymph node metastasis was greater in males ( $p=0.037$ ), patients with multifocality in preoperative US findings $(p=0.026)$, and patients with a tumor located in the isthmus ( $p=0.001)$. Other variables including age, tumor size (clinic and pathologic), extracapsular invasion, and extent of thyroidectomy were not significantly predictive of subclinical lymph node metastasis (Table 1).

Multivariate analysis demonstrated that only tumor location (isthmus; Odds ratio, 4.967; 95\% confidence interval [Cl], 1.175-20.996) was an independent predictor of subclinical central lymph node metastasis, while multifocality showed borderline significance (Table 2). Further statistical analyses assessed corre- 


\section{Subclinical Central Lymph Node Metastasis in Papillary Thyroid Microcarcinoma}

Table 1. Univariate analysis of clinicopathologic factors related to subclinical lymph node metastasis

\begin{tabular}{|c|c|c|c|c|}
\hline Characteristics & Number of patients & pN1a & pNO & $\mathrm{p}$ value \\
\hline \multicolumn{5}{|l|}{ Age } \\
\hline$<45$ yrs & $77(35.2 \%)$ & $23(29.9 \%)$ & $54(70.1 \%)$ & \multirow[t]{2}{*}{0.236} \\
\hline$\geq 45$ yrs & $142(64.8 \%)$ & $39(27.5 \%)$ & $103(72.5 \%)$ & \\
\hline \multicolumn{5}{|l|}{ Gender } \\
\hline Male & $34(15.5 \%)$ & $15(44.1 \%)$ & $19(55.9 \%)$ & \multirow[t]{2}{*}{0.037} \\
\hline Female & $185(84.5 \%)$ & $47(25.4 \%)$ & $138(74.6 \%)$ & \\
\hline \multicolumn{5}{|l|}{ Size (clinical) } \\
\hline$\leq 5 \mathrm{~mm}$ & $64(29.2 \%)$ & $17(26.6 \%)$ & 47 (73.4\%) & \multirow[t]{2}{*}{0.745} \\
\hline$>5 \mathrm{~mm}$ & $155(70.8 \%)$ & $45(29.0 \%)$ & $110(71.0 \%)$ & \\
\hline \multicolumn{5}{|l|}{ Size (pathologic) } \\
\hline$\leq 5 \mathrm{~mm}$ & $89(40.6 \%)$ & $23(25.8 \%)$ & $66(74.2 \%)$ & \multirow[t]{2}{*}{0.544} \\
\hline$>5 \mathrm{~mm}$ & $130(59.3 \%)$ & $39(30.0 \%)$ & $91(70.0 \%)$ & \\
\hline \multicolumn{5}{|l|}{ pT } \\
\hline pT1a & $142(64.8 \%)$ & $39(27.5 \%)$ & $103(72.5 \%)$ & \multirow[t]{2}{*}{0.754} \\
\hline pT3, pT4 & 77 (35.2\%) & $23(29.9 \%)$ & $54(70.1 \%)$ & \\
\hline \multicolumn{5}{|l|}{ Multifocality } \\
\hline No & $174(79.5 \%)$ & $43(24.7 \%)$ & $131(75.3 \%)$ & \multirow[t]{2}{*}{0.026} \\
\hline Yes & $45(20.5 \%)$ & $19(42.2 \%)$ & $26(57.8 \%)$ & \\
\hline \multicolumn{5}{|c|}{ Tumor location (solitary lesion) } \\
\hline Upper $1 / 3$ & $24(13.8 \%)$ & $6(25 \%)$ & $18(75 \%)$ & \multirow[t]{4}{*}{0.001} \\
\hline Middle $1 / 3$ & $108(62.1 \%)$ & $19(17.6 \%)$ & 89 (82.4\%) & \\
\hline Lower $1 / 3$ & $28(16.1 \%)$ & $9(32.1 \%)$ & $19(67.9 \%)$ & \\
\hline Isthmus & $14(8.0 \%)$ & $9(64.3 \%)$ & $5(35.7 \%)$ & \\
\hline \multicolumn{5}{|l|}{ Operation extent } \\
\hline TT with CND & $118(53.9 \%)$ & $37(31.4 \%)$ & $81(68.6 \%)$ & \multirow[t]{2}{*}{0.296} \\
\hline Lob with CND & $101(46.1 \%)$ & $25(24.8 \%)$ & $76(75.2 \%)$ & \\
\hline
\end{tabular}

$\mathrm{TT}$ : total thyroidectomy, CND: central neck dissection, Lob: lobectomy

Table 2. Multivariate analysis of clinicopathologic factors related to subclinical lymph node metastasis

\begin{tabular}{lcccccr}
\multicolumn{1}{c}{ Factors } & B (SE) & & & & \multicolumn{2}{c}{$95 \% \mathrm{Cl}$ Odd ratio } \\
\cline { 5 - 6 } & & & & Odd ratio & Lower & Upper \\
\hline Gender & $0.547(0.463)$ & 0.237 & 1.729 & 0.698 & 4.281 \\
Multifocality & $1.097(0.627)$ & 0.080 & 2.996 & 0.876 & 10.243 \\
Tumor location (solitary lesion) & $1.603(0.735)$ & 0.029 & 4.967 & 1.175 & 20.996 \\
\hline
\end{tabular}

SE: standard error of estimates, Cl: confidence interval

Table 3. Multivariate analysis of clinicopathologic factors relate to papillary thyroid microcarcinoma of isthmus

\begin{tabular}{|c|c|c|c|c|c|}
\hline \multirow{2}{*}{ Factors } & \multirow{2}{*}{$\mathrm{B}(\mathrm{SE})$} & \multirow{2}{*}{ p value } & \multirow{2}{*}{ Odd ratio } & \multicolumn{2}{|c|}{$95 \% \mathrm{Cl}$ Odd ratio } \\
\hline & & & & Lower & Upper \\
\hline pT & $0.850(0.452)$ & 0.060 & 2.340 & 0.966 & 5.669 \\
\hline $\mathrm{pN}$ & $1.496(0.454)$ & 0.001 & 4.464 & 1.832 & 10.877 \\
\hline Multifocality & $1.193(0.465)$ & 0.010 & 3.296 & 1.324 & 8.202 \\
\hline
\end{tabular}

SE: standard error of estimates, $\mathrm{Cl}$ : confidence interval

lation of tumors involving the isthmus with subclinical lymph node metastasis. Number of lymph nodes $(p=0.360)$ and LD ( $p=0.191)$ were not significantly related to PTMC of isthmus. Tumors involving the isth- mus were statistically related to the presence of ETE $(p=0.034)$, multifocality $(p=0.01)$, and cervical lymph node metastasis ( $p=0.001)$; were confirmed by multivariate analysis (Table 3). We also analyzed the cor- 
Table 4. Location of solitary lesion and location of central lymph node metastasis

\begin{tabular}{lrrr}
\hline Tumor location & Ipsilateral paratracheal LN & Pretracheal $L N$ & Contralateral paratracheal $L N$ \\
\hline Upper $1 / 3$ & $5 / 24(20.8 \%)$ & $2 / 24(8.3 \%)$ & $1 / 6(16.7 \%)$ \\
Middle $1 / 3$ & $14 / 108(13.0 \%)$ & $6 / 108(5.6 \%)$ & $4 / 19(21.1 \%)$ \\
Lower $1 / 3$ & $7 / 28(25.0 \%)$ & $2 / 28(7.1 \%)$ & $2 / 9(22.2 \%)$ \\
Isthmus & $5 / 14(35.7 \%)$ & $7 / 14(50.0 \%)$ & $2 / 9(22.2 \%)$ \\
Total $(n=187)$ & $31 / 174(19.3 \%)$ & $17 / 174(9.8 \%)$ & $9 / 43(20.9 \%)$ \\
p value & 0.115 & 0.001 & 0.994 \\
\hline
\end{tabular}

LN: lymph node

relation between the locations of single lesions and the locations of central lymph node metastasis. Ipsilateral and contralateral paratracheal lymph node metastasis were not statistically related to the locations of single lesions, but pretracheal lymph node metastasis was significantly related to PTMC of isthmus ( $p=0.001)$. Seven of fourteen subjects (50\%) had pretracheal lymph node metastasis (Table 4). Univariate analysis revealed that there was no significant relationship between the number of lymph node metastasis or LD and the clinicopathologic factors with PTMC of the isthmus.

\section{Discussion}

Although PTMC shows a relatively favorable prognosis and progresses slowly in most cases, there is a considerable possibility of central lymph node metastasis and ETE. Therefore the optimal surgical treatment especially in the CND for the PTMC, continues to be the subject of considerable debate.

Some studies recommend that small papillary thyroid carcinomas may not need to be treated when incidentally detected or if follow-up US shows little or no growth. ${ }^{9,10)}$ Additionally, some studies assert that nodal recurrence does not differ between the prophylactic dissection group and the no-dissection group in PTMC. ${ }^{11)}$ But other study suggests PTMC should be observed and treated the same as PTC since PTMC has $26.8 \%$ ETE rate and $11.9 \%$ lymph node metastasis. ${ }^{6)}$ In the current study, occult metastasis to the central neck compartment was found in $37.5 \%$ of the CND patients. Some pathologic examinations of routinely dissected neck node specimens have indicated that neck lymph node metastasis can occur from
$47.0 \%$ to $64.1 \%$ of patients with PTMC. ${ }^{3,11)}$

Our study is also in agreement with many studies that revealed the presence of considerable lymph node metastasis in intraglandular cT1aNO PTMC. These pathologic findings of PTMC having a high tendency for regional metastasis seem to justify performing routine CND in PTMC. ${ }^{12)}$ Moreover, since cervical lymph node metastasis often is hard to detect in preoperative imaging studies, it is possible that metastasis of PTMC to lateral or central compartment cervical lymph nodes are overlooked.

We have also assessed the predictive factors of subclinical central lymph node metastasis in 219 intracapsular (cT1aNO) PTMC patients who underwent lobectomy or total thyroidectomy with routine central neck dissection. Many studies show that about 37\% to $40.3 \%$ of subclinical central lymph node metastasis are associated with predictive factors, such as male, multifocality, and ETE. ${ }^{6,13)}$ Those study results show higher rate of central lymph node metastasis compare to our study. This discrepancy may be due to our exclusion of PTMC patients with ETE who were diagnosed by preoperative imaging studies.

Several studies have described the relationship between lymph node metastasis and tumor location in solitary PTMC. Zhang et al. ${ }^{7)}$ report that patients with a primary tumor in the lower third have a greater probability of central lymph node metastasis than those with in a primary tumor in the upper third (Odd ratio 14.8). But Wada et al. ${ }^{3)}$ insist that the location of the primary tumor does not predict the pattern of lymph node metastasis. Our study results show that 9 out of 14 patients with PTMC in the isthmic part of the thyroid, have the highest rates of central lymph node metastasis and the presence of ETE and multifocality 
Subclinical Central Lymph Node Metastasis in Papillary Thyroid Microcarcinoma

showed higher rate. Although previous reports regarding surgical strategy for involving the isthmus are very few, some authors like Choi et al. ${ }^{8)}$ recommend bilateral CCND as a primary surgical procedure for PTC and PTMC in the isthmic part of the thyroid.

The main limitations of this study are its retrospective design, and the lack of oncologic outcomes from long-term follow up. Because of the limitation in the retrospective design, there are some inconsistent surgical extent. Further investigation of subclinical central lymph node metastasis leading to recurrence should be included in future research.

\section{Conclusion}

Despite the absence of ETE and lymph node metastasis in preoperative imaging studies, higher risk of subclinical central lymph node metastasis should be considered in PTMC with multifocality and tumor of the isthmus. Therefore, elective CND of ipsilateral paratracheal and pretracheal lymph nodes may be considered for CT1aNO PTMC that is multifocal or located in the isthmus.

\section{References}

1) Roh JL, Kim JM, Park CI. Central cervical nodal metastasis from papillary thyroid microcarcinoma: pattern and factors predictive of nodal metastasis. Ann Surg Oncol 2008;15(9): 2482-6.

2) Hyun SM, Song HY, Kim SY, Nam SY, Roh JL, Han MW, et al. Impact of combined prophylactic unilateral central neck dissection and hemithyroidectomy in patients with papillary thyroid microcarcinoma. Ann Surg Oncol 2012;19(2):591-6.
3) Wada N, Duh QY, Sugino K, Iwasaki H, Kameyama K, Mimura $\mathrm{T}$, et al. Lymph node metastasis from 259 papillary thyroid microcarcinomas: frequency, pattern of occurrence and recurrence, and optimal strategy for neck dissection. Ann Surg 2003;237(3):399-407.

4) Roh JL, Kim JM, Park CI. Lateral cervical lymph node metastases from papillary thyroid carcinoma: pattern of nodal metastases and optimal strategy for neck dissection. Ann Surg Oncol 2008;15(4):1177-82.

5) Giordano D, Gradoni P, Oretti G, Molina E, Ferri T. Treatment and prognostic factors of papillary thyroid microcarcinoma. Clin Otolaryngol 2010;35(2):118-24.

6) Kim YW, Wang SG, Lee JC, Lee BJ, Lee JW, Kim YK, et al. Clinically related factors and features of central compartment neck lymph nodes in thyroid micropapillary carcinoma. Korean J Otorhinolaryngol-Head Neck Surg 2009;52(3):232-6.

7) Zhang L, Wei WJ, Ji QH, Zhu YX, Wang ZY, Wang Y, et al. Risk factors for neck nodal metastasis in papillary thyroid microcarcinoma: a study of 1066 patients. J Clin Endocrinol Metab 2012;97(4):1250-7.

8) Choi SY, Kim JS, Soh EY, Park CH. Clinicopathologic characteristics of papillary carcinoma in the thyroid isthmus. J Korean Surg Soc 2010;78(2):77-81.

9) Harach HR, Franssila KO, Wasenius VM. Occult papillary carcinoma of the thyroid. A "normal" finding in Finland. A systematic autopsy study. Cancer 1985;56(3):531-8.

10) Ito $Y$, Uruno $T$, Nakano $K$, Takamura $Y$, Miya $A$, Kobayashi $\mathrm{K}$, et al. An observation trial without surgical treatment in patients with papillary microcarcinoma of the thyroid. Thyroid 2003;13(4):381-7.

11) Ito $Y$, Tomoda $C$, Uruno $T$, Takamura $Y$, Miya $A$, Kobayashi $\mathrm{K}$, et al. Clinical significance of metastasis to the central compartment from papillary microcarcinoma of the thyroid. World J Surg 2006;30(1):91-9.

12) Choi SJ, Kim TY, Lee JC, Shong YK, Cho KJ, Ryu JS, et al. Is routine central neck dissection necessary for the treatment of papillary thyroid microcarcinoma? Clin Exp Otorhinolaryngol 2008; 1(1):41-5.

13) Baudin E, Travagli JP, Ropers J, Mancusi F, Bruno-Bossio G, Caillou B, et al. Microcarcinoma of the thyroid gland: the Gustave-Roussy Institute experience. Cancer 1998;83(3):553-9. 